\title{
Helicobacter pylori lipopolysaccharide modification, Lewis antigen expression, and gastric colonization are cholesterol-dependent Ellen Hildebrandt and David J McGee*
}

Address: Department of Microbiology and Immunology, Louisiana State University Health Sciences Center - Shreveport, 1501 Kings Highway, Shreveport, LA 71130, USA

Email: Ellen Hildebrandt - hildejob@lycos.com; David J McGee* - dmcgee@Isuhsc.edu

* Corresponding author

Published: 14 December 2009

BMC Microbiology 2009, 9:258 doi:10.1| 86//47|-2/80-9-258

This article is available from: http://www.biomedcentral.com//47/-2/80/9/258

(c) 2009 Hildebrandt and McGee; licensee BioMed Central Ltd.

This is an Open Access article distributed under the terms of the Creative Commons Attribution License (http://creativecommons.org/licenses/by/2.0), which permits unrestricted use, distribution, and reproduction in any medium, provided the original work is properly cited.
Received: 16 June 2009

Accepted: 14 December 2009

\begin{abstract}
Background: Helicobacter pylori specifically takes up cholesterol and incorporates it into the bacterial membrane, yet little is currently known about cholesterol's physiological roles. We compared phenotypes and in vivo colonization ability of $H$. pylori grown in a defined, serum-free growth medium, FI2 with I mg/ml albumin containing 0 to $50 \mu \mathrm{g} / \mathrm{ml}$ cholesterol.

Results: While doubling times were largely unaffected by cholesterol, other overt phenotypic changes were observed. $H$. pylori strain SSI grown in defined medium with cholesterol successfully colonized the stomach of gerbils, whereas SSI grown without cholesterol failed to colonize. $H$. pylori lipopolysaccharide often displays Lewis $X$ and/or $Y$ antigens. Expression of these antigens measured by whole-cell ELISA was markedly enhanced in response to growth of strain SSI, 26695, or G27 in cholesterol. In addition, electrophoretic analysis of lipopolysaccharide in wild type G27 and in mutants lacking the O-chain revealed structural changes within the oligosaccharide core/lipid A moieties. These responses in Lewis antigen levels and in lipopolysaccharide profiles to cholesterol availability were highly specific, because no changes took place when cholesterol was substituted by $\beta$-sitosterol or bile salts. Disruption of the genes encoding cholesterol $\alpha$ glucosyltransferase or lipid A phosphoethanolamine transferase had no effect on Lewis expression, nor on lipopolysaccharide profiles, nor on the cholesterol responsiveness of these properties. Disruption of the lipid A I-phosphatase gene eliminated the effect of cholesterol on lipopolysaccharide profiles but not its effect on Lewis expression.

Conclusions: Together these results suggest that cholesterol depletion leads to aberrant forms of LPS that are dependent upon dephosphorylation of lipid A at the I-position. A tentative model for the observed effects of cholesterol is discussed in which sequential steps of lipopolysaccharide biogenesis and, independently, presentation of Lewis antigen at the cell surface, depend upon membrane composition. These new findings demonstrate that cholesterol availability permits $H$. pylori to modify its cell envelope in ways that can impact colonization of host tissue in vivo.
\end{abstract}

\section{Background}

Helicobacter pylori is a highly niche-adapted pathogen that inhabits the human stomach, is transmitted primarily within families, and has no known environmental reservoir. Chronic infections may be asymptomatic or cause gastritis, ulcer, or gastric cancer. To establish infection, the 
bacterium must survive transit through the acidic gastric compartment [1]. It penetrates and establishes residence in the protective mucus layer, a lipid- and cholesterol-rich environment $[2,3]$. Within this niche the bacterium employs a variety of mechanisms to evade host immune response.

Lipopolysaccharides (LPS) on the surface of $H$. pylori are modified to display certain human blood group antigens, primarily Lewis antigens $\mathrm{X}$ and $\mathrm{Y}$ [4-7], and less frequently $\mathrm{H}$ type 1, i-antigen, blood group A, or Lewis antigens A or $B$ [8-10]. These surface LPS antigens are necessary for the establishment of infection, because mutant strains defective for LPS O-antigen synthesis or for Lewis X/Y expression fail to colonize mice [11-13]. There is evidence that Lewis antigens expressed on the bacterial surface contribute to adherence of $H$. pylori to gastric epithelial cells $[10,14]$, and play a role in tissue tropism [15-17]. Gastric epithelial cells also express Lewis antigens $[18,19]$, suggesting that the display of Lewis antigens on the bacterial surface may serve as a mimicry strategy. Studies of clinical isolates $[18,20]$ and experimental infections in animals [21] support this role for bacterial Lewis antigens in immune evasion. In human infection, $H$. pylori Lewis antigens have been linked to the severity of peptic ulcer and duodenitis [16,22]. Another important feature of $H$. pylori LPS is its modified lipid A structure, with reduced acylation and fewer charged groups than is typical of enterobacteria [23]. These lipid A modifications minimize endotoxic and inflammatory properties of $H$. pylori LPS (reviewed in [24]).

Cholesterol is a nonessential nutrient for $H$ pylori, though it promotes growth in serum-free media $[25,26]$. H. pylori specifically incorporate cholesterol into the bacterial membrane [27], as do a limited number of pathogenic and commensal bacteria including Proteus mirabilis, Lactobacillus acidophilus, Borrelia sp., and Mycoplasma [28-30]. Cholesterol may strengthen the membrane in these organisms [30-32]. H. pylori also uniquely form cholesterol $\alpha$-glycoside $[33,34]$, and this metabolite can be further modified by acylation or phosphatidylation [34]. Alpha-glucosylated cholesterol subverts host immune response to the bacterium in a mouse model, through suppression of phagocytosis and of T cell activation [35]. Other roles for cholesterol and cholesterol metabolites in the bacterial membrane have yet to be explored. In this report, we demonstrate that the biosynthesis of lipopolysaccharide, including Lewis antigen expression and LPS core/lipid A modification, are altered by availability of cholesterol in the growth medium. We present data indicating that these changes in the cell envelope may significantly influence the pathogen/host interaction in an animal model of infection.

\section{Methods}

\section{Bacterial strains and growth conditions}

Strains of $H$ pylori included the laboratory strain ATCC43504 (origin: Australia), 26695 (UK), clinical isolate G27 (Italy [36], provided by N. Salama), and the mouse adapted strain SS1 (Australia; provided by Adrian Lee [37]). Bacteria were maintained at $37^{\circ} \mathrm{C}$ in a microaerobic atmosphere of $5 \% \mathrm{O}_{2} / 10 \% \mathrm{CO}_{2}$ on Campylobacter blood agar (CBA). Bacteria were passaged every 2 to 3 days, and for no more than 25 days, to minimize genetic drift. For growth in chemically defined medium [26], bacteria were inoculated from CBA into tissue culture flasks containing Ham's F12 (Gibco) with $1 \mathrm{mg} / \mathrm{ml}$ bovine serum albumin (fatty acid-free, Sigma A7906), referred to throughout as defined medium. Liquid cultures were passaged daily by dilution into fresh medium at initial densities of $1-2 \times 10^{6} / \mathrm{ml}$, and used at passage 3 to 5 . Cell culture grade cholesterol ( $>99 \%$, Sigma) was added to F12 as a stable $10 \times$ emulsion containing $500 \mu \mathrm{g} / \mathrm{ml}$ cholesterol dispersed in $10 \mathrm{mg} / \mathrm{ml}$ albumin, which was prepared according to [38]. The following media additions were carried out in like manner: $\beta$-sitosterol (synthetic, 95\%), sodium taurocholate, sodium glycocholate, $\beta$-estradiol, progesterone (all from Sigma), dehydroepiandrosterone (Calbiochem), and $\beta$-coprostanol (Matreya).

Doubling times were determined during log phase growth by quantitating viable cells using the Cell Titer Glo reagent (Promega) as validated and described [39]. Measurement of biomass as CFU, as cellular protein, or as ATP have all produced consistent results. A value of 1 attomol ATP per cell [40] was assumed for routine passage. Possible inaccuracy of this value does not fundamentally influence interpretation of data.

Isogenic gene disruptions were achieved by insertion of a Campylobacter coli chloramphenicol resistance element (cat) according to the strategy described by Chalker et al [41]. Primers were carefully designed so as to target sequence within open reading frames, and are listed in Table 1. Fusion PCR reactions using the PCR Extender System (5Prime) contained $2.3 \mathrm{nM}$ each gel-purified template, $50 \mu \mathrm{M}$ primer, $1 \times$ tuning buffer, $1.25 \mathrm{mM}$ additional $\mathrm{Mg}^{++}, 0.2 \mathrm{mM}$ each $\mathrm{dNTP}$, and $.01 \mathrm{U} / \mu \mathrm{l}$ polymerase. Fusion cycle conditions were as follows: $94^{\circ} \mathrm{C} 2.5 \mathrm{~min}, 10$ cycles $\left[94^{\circ} \mathrm{C} 15 \mathrm{sec}, 45^{\circ} \mathrm{C} 60 \mathrm{sec}, 68^{\circ} \mathrm{C}\right.$ $60 \mathrm{sec}$ per kb], 25 cycles [ $94^{\circ} \mathrm{C} 15 \mathrm{sec}$, primer-specific Tm $30 \mathrm{sec}, 68^{\circ} \mathrm{C} 60 \mathrm{sec}$ per $\mathrm{kb}$ ], final extension $68^{\circ} \mathrm{C}$ 6-8 min. Fusion products were reamplified with Pfx50 (Invitrogen) to increase quantity, then purified using the Qiaquick PCR Purification Kit (Qiagen). Recipient strains grown 1 day on CBA were transformed with $500 \mathrm{ng}$ of the final amplicon using natural transformation $[42,43]$ followed by selection for 7-10 days on CBA containing $15 \mu \mathrm{g} / \mathrm{ml}$ chloramphenicol. To ensure allelic replacement, the 
Table I: Primer sequences.

\begin{tabular}{|c|c|c|}
\hline \multicolumn{3}{|c|}{ primers for allelic disruption ${ }^{a}$} \\
\hline CAT fwd [4I] & GATATAGATTGAAAAGTGGAT & $\mathrm{F} 5 \mathrm{~b}$ \\
\hline CAT rev [4I] & TTATCAGTGCGACAAACTGGG & \\
\hline cgtfwd & atggttattgttttagtcgtgga & \\
\hline cgtM3 & ATCCACTTTTCAATCTATATCatatggtggatatagcggtaatg & \\
\hline cgtM5 & CCCAGTTTGTCGCACTGATAAttaaaaacttgcaccctttatgt & \\
\hline cgtrev & ctctgatcgcttcttcataaact & \\
\hline pmifwd & atgaaaattaaaaatatcttactgagtggg & \\
\hline pmiM3 & ATCCACTTTTCAATCTATATCatctaaaccattagggctttcaatatac & \\
\hline pmiM5 & CCCAGTTTGTCGCACTGATAActttagtgaacgaggtagaaacaaac & \\
\hline pmirev & ttttgtctgttaaaatcatcatcaat & \\
\hline IpxE fwd & atgaaaaaattcttatttaaacaaaaattttgtgaaagc & \\
\hline IpxEM3 & ATCCACTTTTCAATCTATATCcccaaacgctgatcgttgat & \\
\hline IpxEM5 & CCCAGTTTGTCGCACTGATAAcgagcgcccttatggag & \\
\hline IpxErev & ttaaggctttttggggcttgtaaa & \\
\hline eptAfwd & ttggcatcattattccatctgaggt & \\
\hline eptAM3 & ATCCACTTTTCAATCTATATCgcaacaccccaaaaacaacgata & \\
\hline eptAM5 & CCCAGTTTGTCGCACTGATAAagcctgattaacgcctatgaca & \\
\hline eptArev & ttactcttttttgtgtttaagcagatctaaagaa & \\
\hline \multicolumn{3}{|c|}{ additional primers for confirmation of gene disruption } \\
\hline G27_95Ifwd & agtgattcaagatggcgtgaaaa & $\mathrm{FI}$ \\
\hline G27_953rev & ccaagctcaatcatttctttgtcttt & $\mathrm{RI}$ \\
\hline G27_37fwd & cggcatggggatcaatcaag & $\mathrm{F} 2$ \\
\hline G27_39rev & ctcccgtcttgcccggtaac & R2 \\
\hline G27I9fwd & gggcgataaaatcgtgtttca & F3 \\
\hline G272I rev & tcccctttatcgtttatgctaatga & R3 \\
\hline G2720fwd & cccaaactgagcgctaaca & $\mathrm{F} 4$ \\
\hline G2722rev & aagaaatttcaaggtataatagtttccaag & R4 \\
\hline
\end{tabular}

aRespective gene numbers in public databases for 26695 and G27 are as follows: [cgt: hp042 I, G27_952], [pmi (rfbM): hp0043, G27_38], [lpxE: hp002I, G27_20], [eptA: hp0022, G27_2I].

bRighthand column lists the brief primer designations used in Figure I. 
resultant strains were evaluated by PCR of the genomic DNA using GoTaq (Promega) with primers specified in Table 1. PCR strategy and results are shown in Figure 1.

\section{Gastric colonization}

Animal experiments were approved by the LSUHSCS Institutional Animal Care and Use Committee. Female Mongolian gerbils were maintained on ordinary diet ad libitum. To preserve motility, H. pylori strain SS1 was cultured overnight under microaerobic conditions in T75 flasks containing $40 \mathrm{mls}$ of F12 medium with $0.4 \mathrm{mg} / \mathrm{ml}$ albumin and 0 or $50 \mu \mathrm{g} / \mathrm{ml}$ cholesterol. The motile planktonic bacteria were harvested by centrifugation and resuspended in isotonic saline. Colony forming units (CFU) were measured in these inocula by serial dilution and plating on $\mathrm{CBA}$, and these measurements confirmed equal dosage of viable bacteria between the two growth conditions. Approximately $10^{8} \mathrm{CFU}$ per $30 \mu \mathrm{l}$ were given orally to animals ( $\mathrm{n}=6$ to 9 per group). Animals were euthanized 11 days later, and stomachs were removed and dissected. $H$. pylori present in gastric antrum homogenates were quantitated by serial dilution and plating on CBA containing 5 -fluorocytosine $(5 \mu \mathrm{g} / \mathrm{ml})$, vancomycin $(10$ $\mu \mathrm{g} / \mathrm{ml})$, amphotericin B $(5 \mu \mathrm{g} / \mathrm{ml})$, bacitracin $(30 \mu \mathrm{g} / \mathrm{ml})$, polymyxin B $(10 \mathrm{U} / \mathrm{ml})$, and trimethoprim $(10 \mu \mathrm{g} / \mathrm{ml})$ [44]. Duplicate CFU determinations were made for multiple dilutions of each tissue sample.

\section{Whole-cell ELISA}

Standard procedures $[6,7,45]$, were adapted for the use of peroxidase conjugated secondary antibody. All antibodies were obtained from Calbiochem. Overnight cultures of

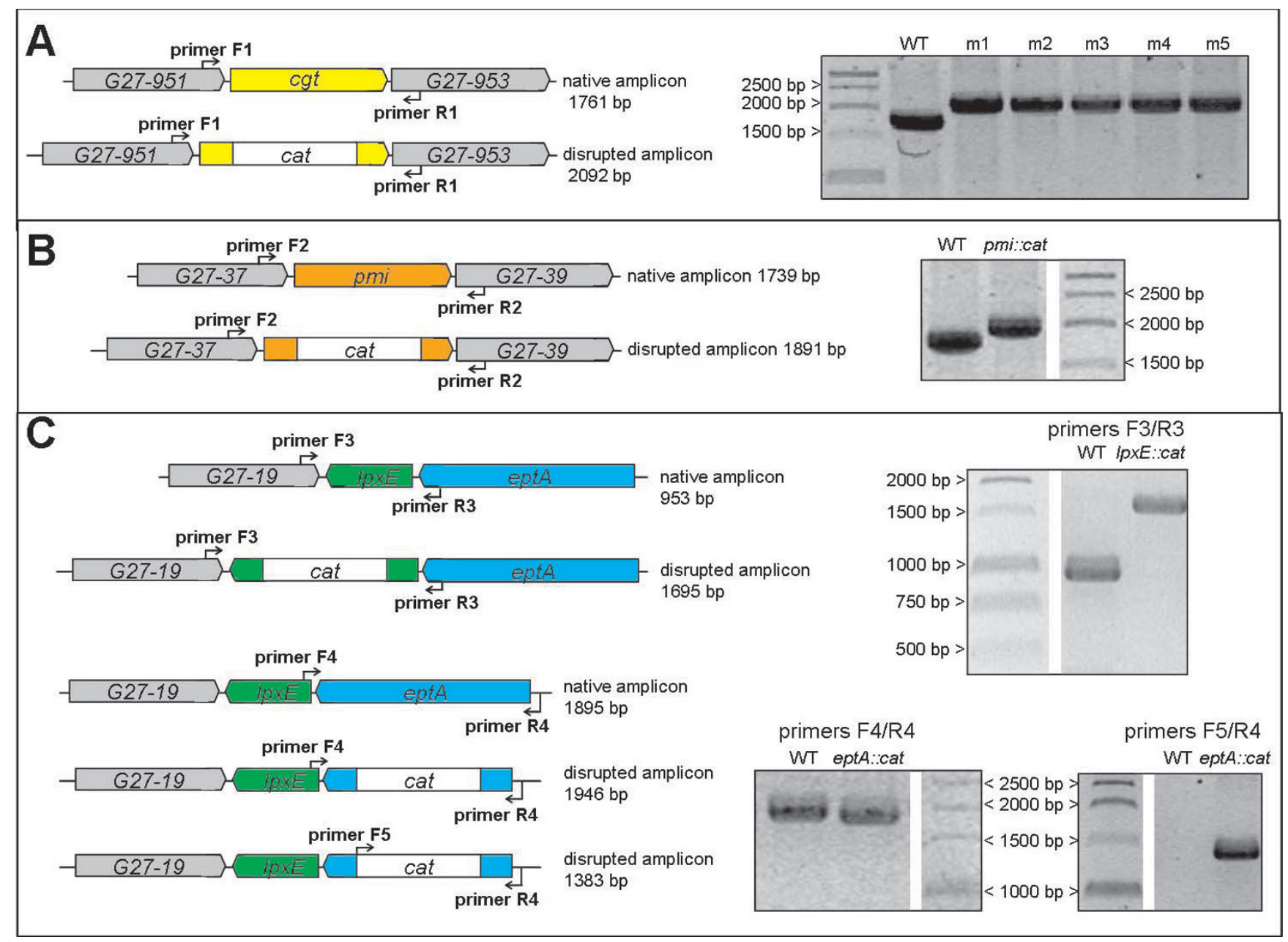

\section{Figure I}

PCR verification of allelic disruptions in $\boldsymbol{H}$. pylori strain $\mathbf{G 2 7}$. Genomic DNA was prepared from gene-disrupted G27 strains following three passages under chloramphenicol selection, then PCR amplified as shown in each scheme. Primers sequences are given in Table I. A. Disruption of cgt. Five examples are shown out of seven individual clones, all of which gave identical results in the screen. B. Disruption of pmi (rfbM). The entire chloramphenicol-resistant population was passaged in each round of selection, without clonal selection. C. Disruption of IpxE and eptA. The entire chloramphenicolresistant population was passaged in each round of selection, without clonal selection. 
bacteria were collected by centrifugation at $3500 \times \mathrm{g}$ for 10-15 min, washed in Dulbecco's phosphate buffered saline, and repelleted at $10,000 \times g$ for $2 \mathrm{~min}$, then resuspended in $15 \%$ glycerol $/ 0.9 \% \mathrm{NaCl}$. The cell suspensions were assayed for protein content and stored at $-20^{\circ} \mathrm{C}$. Cell samples containing known amounts of protein were rapidly diluted into $50 \mathrm{mM}$ sodium bicarbonate/carbonate pH 9.55 and dispensed immediately into wells of an ELISA plate (Costar \#9017). Plates were sealed and refrigerated overnight, then blocked for $90 \mathrm{~min}$ in 3\% bovine serum albumin dissolved in the wash buffer which consisted of $0.1 \mathrm{M}$ sodium phosphate $\mathrm{pH}$ 7.4/0.1 M NaCl/ $0.1 \% \mathrm{w} / \mathrm{v}$ Tween-20. Primary antibody, monoclonal antiLewis X (Signet clone P12) or anti-Lewis Y (Signet clone F3), diluted 1:500 in wash buffer/1\% BSA, was added for 2 hours, followed by four changes of wash buffer. The secondary antibody, a 1:2500 dilution of horseradish peroxidase-conjugated goat anti-mouse IgM in wash buffer/1\% BSA, was added for $90 \mathrm{~min}$, followed by four changes of wash buffer. The chromogenic substrate was $0.42 \mathrm{mM}$ tetramethylbenzidine and $0.02 \% \mathrm{H}_{2} \mathrm{O}_{2}$ in $50 \mathrm{mM}$ acetate/ citrate $\mathrm{pH} 5.5$ [46]. After 15 minutes at room temperature, reaction was stopped with $1 / 5$ th vol $2.5 \mathrm{~N} \mathrm{H}_{2} \mathrm{SO}_{4}$, and color change was measured in a plate reader at $450 \mathrm{~nm}$. In negative controls omitting either primary or secondary antibody, or with E. coli strain HB101 substituted for $H$. pylori, color change was negligible $(\mathrm{A}<0.05)$. Levels of Lewis $Y$ were negligible $(A<0.1)$ in strain 26695 or 43504 , as were Lewis X levels in SS1.

\section{Electrophoretic analyses of lipopolysaccharides}

$H$. pylori cultures were collected as described above, and washed cell pellets were stored at $-70^{\circ} \mathrm{C}$. Cells were lysed in $60 \mathrm{mM}$ Tris $\mathrm{HCl} \mathrm{pH} 6.8$ containing $2 \%$ SDS at $95-98^{\circ} \mathrm{C}$ for $10 \mathrm{~min}$. Protein content was measured using the bicinchoninic acid assay (Pierce). Samples of cell lysates were adjusted to equal protein content $(1 \mathrm{mg} / \mathrm{ml})$, then proteolyzed in reactions containing (final) $60 \mathrm{mM}$ Tris $\mathrm{HCl} \mathrm{pH}$ $6.8,0.67 \%$ SDS, and $0.67 \mathrm{mg} / \mathrm{ml}$ proteinase $\mathrm{K}$ at $60^{\circ} \mathrm{C}$ for 2 hours [47]. To eliminate electrophoretic artifacts due to the presence of lipid/detergent complexes, proteolyzed samples were extracted with hot phenol [48]. Control experiments verified that all LPS bands were recovered through the following extraction procedure qualitatively and without bias. Proteolyzed samples were mixed with 1 volume of $90 \%$ aqueous phenol and incubated at $70^{\circ} \mathrm{C}$ for $20 \mathrm{~min}$. After cooling to $10^{\circ} \mathrm{C}$ for $1 \mathrm{~min}$, the samples were centrifuged at $12,000 \times g$ for $20 \mathrm{~min}$ at $10^{\circ} \mathrm{C}$, and the aqueous phase collected. The phenolic phases were reextracted with 1 volume of $\mathrm{H}_{2} \mathrm{O}$ at $70^{\circ} \mathrm{C}$ for $10 \mathrm{~min}$, and the centrifugation repeated. The combined aqueous extracts were adjusted to $0.5 \mathrm{M} \mathrm{NaCl}$ and precipitated with $10 \mathrm{vol}$ ethanol in the refrigerator overnight, then centrifuged at $20,000 \times g$ for $20 \mathrm{~min}$ at $10^{\circ} \mathrm{C}$ and air dried. Purified LPS samples were redissolved in Laemmli sample buffer [49] at $95^{\circ} \mathrm{C}$ for $5 \mathrm{~min}$. Samples were applied to $15 \%$ polyacrylamide $/ 0.9 \%$ bis minigels containing $3.2 \mathrm{M}$ urea with the Laemmli discontinuous buffer formulation [49], and a 5\% stacking gel. After electrophoresis at $150 \mathrm{~V}$ for $75 \mathrm{~min}$, gels were either fixed overnight for silver staining [50] or transferred to polyvinylidenedifluoride membrane using Tris/glycine transfer buffer [51]. Blots were blocked overnight in $3 \%$ bovine serum albumin and $0.03 \% \mathrm{NaN}_{3}$ in the wash buffer described above for ELISA. Primary antibody (anti-Lewis X or anti-Lewis Y, 1:200) and secondary antibody (peroxidase-conjugated goat anti-mouse IgM, 1:1000) were diluted in wash buffer containing $0.5 \%$ BSA. Colorimetric detection used 3,3'diaminobenzidine with cobalt enhancement [52]. Densitometry was performed with the public domain application Image J, available at http://rsb.info.nih.gov/ij.

\section{Results}

Little is known about the physiologic roles of cholesterol in $H$. pylori. To investigate responses of $H$. pylori to cholesterol, we adopted a defined, serum-free culture medium, F12 with $1 \mathrm{mg} / \mathrm{ml}$ albumin, in which this bacterium may be stably passaged [26]. This modest concentration of albumin boosts growth $[25,26]$ and alleviates the tight adherence to culture surfaces that occurs in protein-free media [53]. In this defined medium, addition of $50 \mu \mathrm{g} / \mathrm{ml}$ cholesterol did not significantly alter the growth rate (Figure 2). The absence of growth effects under the chosen culture conditions was advantageous for investigation of the physiological importance of cholesterol in H. pylori. Thus, we were able to compare gastric colonization of gerbils by strain SS1 that had been cultured in the defined medium containing varied amounts of cholesterol (Figure 3). Eleven days after oral inoculation, $H$. pylori in gastric antrum were selectively plated and quantitated. Strikingly, gerbils were colonized only by the cultures grown in cholesterol-containing medium, but not by $H$. pylori grown in cholesterol-free medium (In each experiment, $\mathrm{P}<.0001$ for comparison of $\log (\mathrm{CFU} / \mathrm{g})$ between groups using Student two-tailed t-test). Therefore, cholesterol was an essential component of the growth medium in order to establish $H$. pylori infection in this animal model.

Certain strains of $H$. pylori exhibited significant differences in adherence to culture vessels following passage in cholesterol, suggesting alterations in their cell surface properties (Hildebrandt \& McGee, unpublished observations). For this reason, we decided to investigate lipopolysaccharides, which constitute the principal component of the cell envelope, and serve to present the biologically important Lewis antigens. We employed a well established whole-cell ELISA procedure to quantitate the predominant Lewis antigens, Lewis X and Y (Figure 4). In accordance with the literature $[54,55]$, primarily Lewis $X$ was detected in strain 26695, only Lewis Y was detected in SS1, 


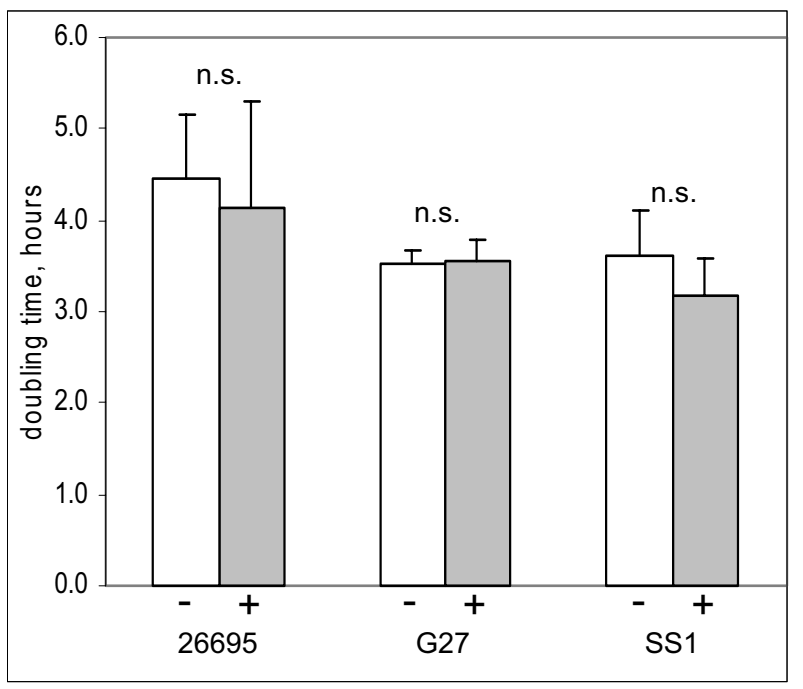

Figure 2

Addition of cholesterol to the defined medium does not affect $\boldsymbol{H}$. pylori growth rate. Parallel cultures of each strain were grown overnight in FI2/albumin $(\mathrm{I} \mathrm{mg} / \mathrm{ml})$ in the absence (open bars) or presence (shaded bars) of $50 \mu \mathrm{g} / \mathrm{ml}$ cholesterol. The initial population density was $2 \times 106 / \mathrm{ml}$. Doubling times were calculated from the measured increase in biomass. Values shown represent the mean $\pm \mathrm{sd}$ of five or more independent measurements. $n$. s. Student's two-tailed t-test for pairwise data showed no statistical significance.

and significant levels of both were detected in G27. In each case, absorbance readings were nonlinear with respect to sample load, an occurrence that is not unusual in ELISA assays [56], and that has been noted by other investigators using these same monoclonals [7]. Thus, in order to compare antigen levels in samples of $H$. pylori cultured in the absence or presence of cholesterol, we performed parallel titrations over a range of sample loadings varying from 20 to $500 \mathrm{ng}$ of cell protein per well. These titrations reproducibly showed a marked increase in the amount of Lewis $\mathrm{X}$ and/or Lewis $\mathrm{Y}$ antigen detected on the cell surface when $H$. pylori strains 26695, SS1 or G27 were cultured in the presence of cholesterol (Figure 4). In replicate independent experiments, the mean cholesteroldependent increases were statistically significant (Table 2). Comparable results have also been obtained for Lewis $\mathrm{X}$ in strain 43504 (data not shown). Spiking samples with cholesterol at the end of the growth period did not alter the amount of Lewis antigen detected by ELISA (Figure $5 \mathrm{~A}$ ). In another control experiment we verified for all four of these strains that the amount of cell protein bound to the wells was unaffected by growth in cholesterol (Figure $5 \mathrm{~B})$. The ELISA results thus established that increased surface expression of Lewis antigens was a legitimate biological response to cholesterol that occurred in all of the

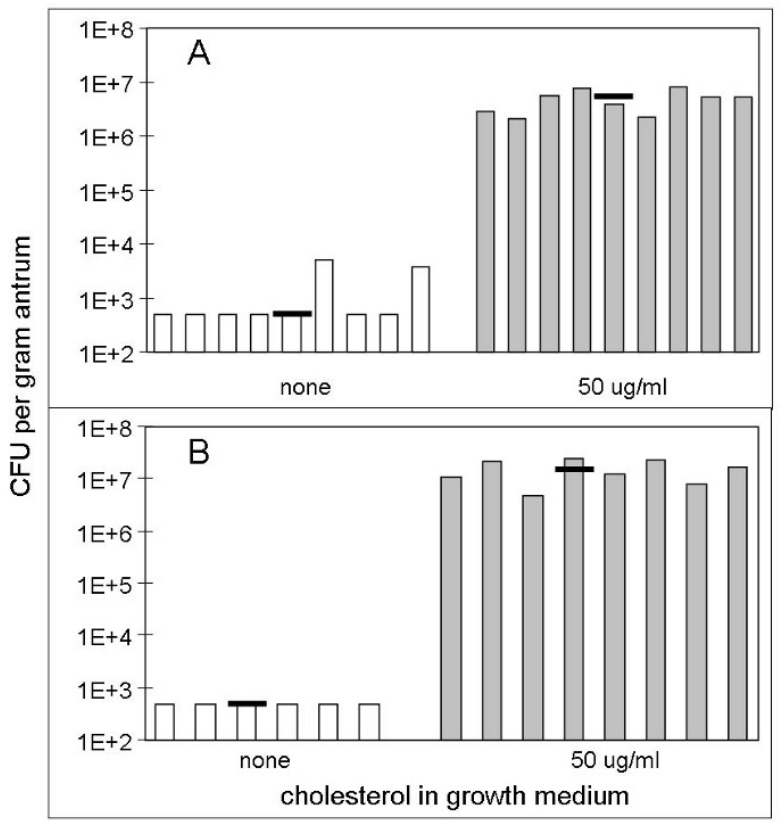

Figure 3

H. pylori grown without cholesterol fail to colonize gerbils. H. pylori strain SSI was grown overnight in defined medium containing 0 or $50 \mu \mathrm{g} / \mathrm{ml}$ cholesterol. Gerbils were orally inoculated with $3.5 \times 10^{8} \mathrm{CFU}$ (experiment $\mathrm{A}$ ) or I $\times$ $10^{8} \mathrm{CFU}$ (experiment B). H. pylori in gastric antrum were quantitated at II days. Each vertical bar represents the mean of duplicate determinations for one animal, and horizontal lines give the median for each treatment group. Where no colonies were recovered, values were recorded as $5 \times 10^{2}$ $\mathrm{CFU} / \mathrm{g}$ tissue, the estimated limit of detection.

strains tested. This response was specific for cholesterol, because substitution of cholesterol in the growth medium with the structural analogs $\beta$-sitosterol or sodium taurocholate had no effect on Lewis X or Y expression by G27 (Figure 4, righthand panels, and Table 3). The Lewis antigen response to cholesterol still remained after disruption of the gene for cholesterol $\alpha$-glucosyltransferase $(c g t)$ in strain G27 (Table 2, and see below) and in 26695 (data not shown), ruling out the participation of $\alpha$-glycoside metabolites of cholesterol.

Detection of Lewis $\mathrm{X}$ and $\mathrm{Y}$ by immunoblotting with the same monoclonal antibodies produced a different result (Figure 6). In several attempts using this technique, we did not detect any cholesterol-dependent differences in Lewis X or Y levels, apart from a small increase in Lewis X in 43504 that was only marginally significant. The blotting procedure employed LPS samples extracted from cell lysates, and in principle should detect the entire cellular Lewis antigen pool, whereas the whole-cell ELISA method is designed to detect only that presented on the extracellular surface. The interesting difference in results between 
Table 2: Enhancement of cell surface Lewis antigen expression by the growth of cultures in the presence of cholesterol.a

\begin{tabular}{|c|c|c|c|c|}
\hline & \multicolumn{4}{|c|}{ fold increase compared to parallel cholesterol-free culture } \\
\hline & \multicolumn{2}{|c|}{ Lewis $\mathbf{X}$} & \multicolumn{2}{|c|}{ Lewis $Y$} \\
\hline & mean \pm SEM (n) & P value & mean \pm SEM (n) & $P$ value \\
\hline 26695 & $4.32 \pm 0.36(6)$ & 0.0002 & not done & \\
\hline SSI & not done & & $1.88 \pm 0.08(5)$ & 0.0004 \\
\hline G27 wild type & $2.85 \pm 0.42(8)$ & 0.0033 & $2.22 \pm 0.24(8)$ & 0.0016 \\
\hline G27 cgt::cat & $3.69 \pm 0.34(5)$ & 0.0013 & $2.88 \pm 0.30(5)$ & 0.0034 \\
\hline G27 IpxE::cat & $2.59 \pm 0.50(6)$ & 0.025 & $2.47 \pm 0.43(7)$ & 0.014 \\
\hline
\end{tabular}

a Lewis antigens were quantitated in replicate whole-cell ELISA analyses of paired samples grown in the presence or absence of $50 \mu \mathrm{g} / \mathrm{ml}$ cholesterol. The antigen load was $300 \mathrm{ng}$ cellular protein per well. Ratios for plus:minus cholesterol were calculated from duplicate net absorbance readings in each assay, and ratios determined in five to eight independent ELISA runs were then averaged. $P$ values were calculated in two-tailed Student $\mathrm{t}$-tests for the null hypothesis that the ratio equals I.

our ELISA analyses and immunoblots suggests a change in cellular compartmentation of the Lewis antigen depending upon the availability of cholesterol in the growth medium.

In addition to Lewis antigen measurement, we directly compared the lipopolysaccharide profiles between parallel cultures grown in the presence or absence of cholesterol, using gel electrophoresis and silver staining. In all the $H$. pylori strains we have examined, LPS band profiles were identical between cultures grown in defined medium with cholesterol to that obtained in serum-containing medium or on blood agar (data not shown), and as expected $[5,24,55,57]$ these profiles were highly strainspecific. On these gels, cholesterol-responsive LPS bands were most clearly resolved for the strain G27, a clinical isolate (Figures 7,8 ). We confirmed that hot phenol extraction, which we included as an additional purification step, did not alter any of the bands seen on these gels (Figure 7). These analyses reproducibly showed that G27 cultures grown in cholesterol-free medium exhibited at least three additional LPS bands (Figure 8 lanes 2, 5, arrows) that were absent or strongly diminished when cholesterol was provided in the growth medium (lanes 3, 6 ). These bands included one in the core region, one in the $\mathrm{O}$-chain region, and a band with intermediate migra- tion on the gel. The responsive band in the core region (bottom arrow) was absent in plus-cholesterol samples, although on some gels a faint neighboring band could be seen which always migrated somewhat more slowly. Addition of cholesterol to the culture at the end of the growth period and prior to sample workup did not alter the LPS band profile (lane 1). Thus the observed band changes occurred biologically and not artifactually. This LPS response did not occur when the growth medium contained an equimolar amount of synthetic $\beta$ sitosterol (lane 4), which differs from cholesterol by a single ethyl group in the alkyl side chain. Similarly, two bile salts which are well tolerated by $H$. pylori, taurocholate and glycocholate, did not affect LPS profiles (lanes 7, 8). Certain other cholesterol-like substances that we attempted to test proved toxic toward $H$. pylori; these included dehydroepiandrosterone, $\beta$-estradiol, and progesterone, as well as 5$\beta$-coprostanol, a compound occurring in the human gut and differing from cholesterol by one double bond in the steroid nucleus. These findings together indicated that the observed LPS modification was strongly specific for cholesterol.

The same LPS response to growth in cholesterol occurred in transformed G27 strains in which the cholesterol $\alpha$-glucosyltransferase gene had been disrupted (Figure 9A).

Table 3: Enhanced cell surface Lewis antigen expression is cholesterol-specific

fold increase compared to parallel cholesterol-free culture

\begin{tabular}{lcccc} 
& \multicolumn{1}{c}{$\begin{array}{c}\text { Lewis } \mathbf{X} \\
\text { mean } \pm \text { SEM (n) }\end{array}$} & P value & mean \pm SEM (n) & P value \\
\hline cholesterol & $2.96 \pm 0.22(5)$ & .0008 & $2.48 \pm 0.10(4)$ & .0007 \\
$\begin{array}{l}\beta \text { - sitosterol } \\
\text { taurocholate }\end{array}$ & $1.80 \pm 0.47(4)$ & 0.19 & $1.19 \pm 0.13(3)$ & 0.28 \\
\hline
\end{tabular}

Lewis antigens were quantitated in replicate whole-cell ELISA analyses of pairwise cultures of $H$. pylori G27 grown in the presence or absence of 130 $\mu \mathrm{M}$ cholesterol, or an equal concentration of $\beta$-sitosterol or sodium taurocholate. The antigen load was $300 \mathrm{ng}$ cellular protein per well. Ratios for plus:minus cholesterol were calculated from duplicate net absorbance readings in each assay, and ratios determined in three to five independent ELISA runs were then averaged. $P$ values were calculated in two-tailed Student $t$-tests for the null hypothesis that the ratio equals I. 


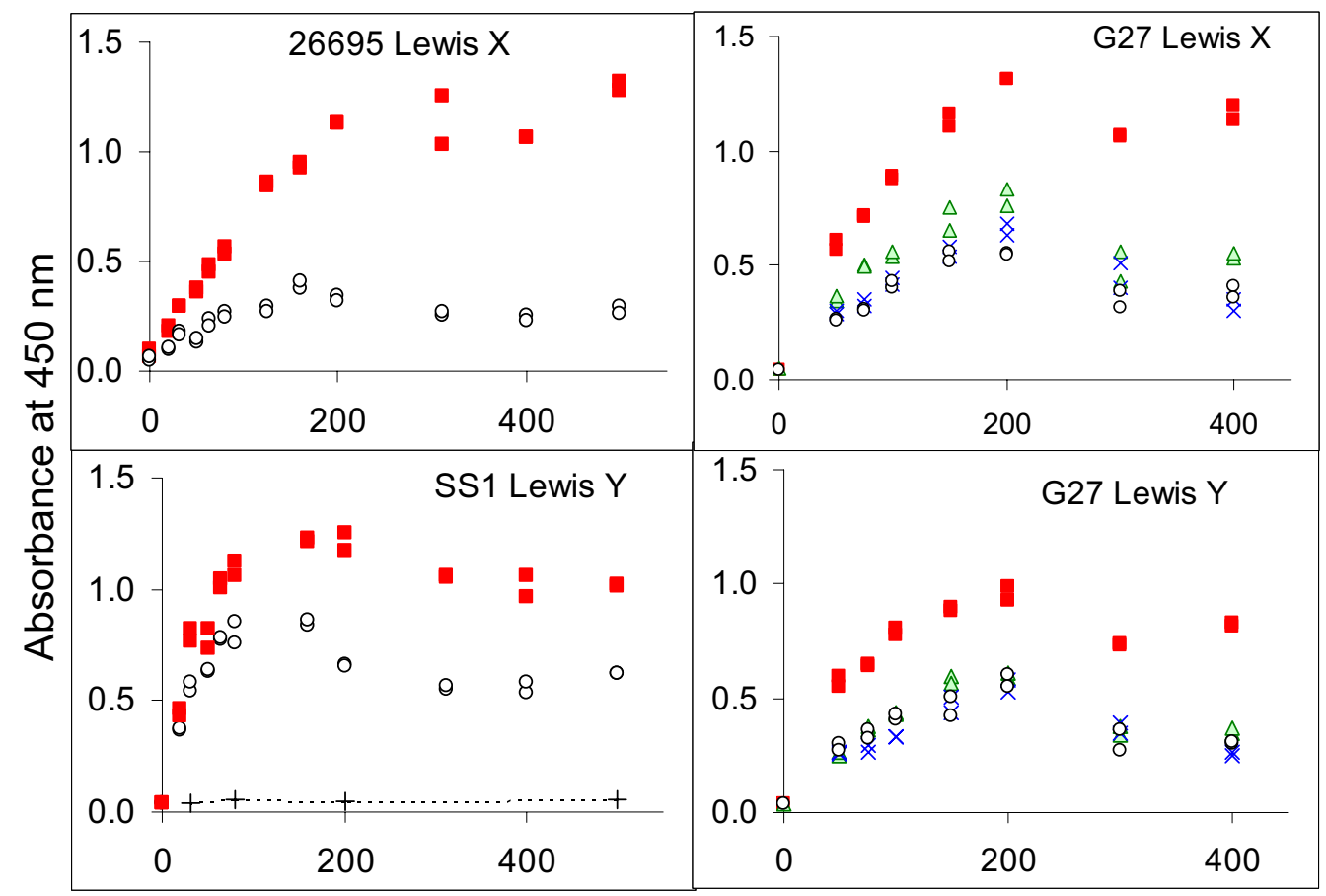

ng protein per well

\section{Figure 4}

Growth in cholesterol specifically enhances cell surface display of Lewis antigens. Whole cell ELISA assays were performed on samples of $H$. pylori strain 26695 (upper left), SSI (lower left), or G27 (upper and lower right). Parallel cultures were grown overnight in defined medium containing $130 \mu \mathrm{M}$ of the following additions: circles, no addition; squares, cholesterol; triangles, $\beta$-sitosterol; $X$, taurocholate. Varying amounts of cell suspension corresponding to known amounts of cellular protein were applied to duplicate wells of ELISA plates, and immunoassayed for the presence of Lewis $X$ or Lewis $Y$ antigen as described in Methods. Negative control samples of E. coli HBIOI, or buffer-only blanks, fell on the dotted line. Absorbance readings for individual wells are plotted. Repeat experiments with three or more independently grown cultures have yielded essentially identical results.

Therefore, $\alpha$-glycoside metabolites of cholesterol were not required for the LPS changes observed on silver-stained gels.

We also investigated cholesterol responsiveness of LPS in a G27 pmi::cat strain lacking O-antigen chains (Figure 9B). As in wild type G27, this strain showed the presence of an additional, more slowly-migrating band in the core region that was diminished or lost upon growth in cholesterol. Likewise, pmi::cat strains of 26695 and SS1 also lacked Ochains, and also exhibited similar cholesterol-dependent band loss in the conserved LPS core region (data not shown). Since LPS species migrating in this region likely include only core oligosaccharide and lipid A moieties, we directed our attention to these components in trying to identify specific cholesterol-dependent structural modifications. We selectively disrupted two lipid A modification genes, either $l p x E$ or eptA, encoding the lipid A 1-phosphatase and lipid A phosphoethanolaminetransferase, respectively [58]. Then, LPS profiles were compared in pairwise cultures of these mutated G27 strains grown in the presence or absence of cholesterol (Figure 9C). We found that the eptA::cat strain retained an LPS response to cholesterol that was even more distinct than in the wild type. In contrast, cholesterol-responsive bands were abolished in the lpxE::cat strain. These results implied that the aberrant bands which accumulated under conditions of cholesterol depletion in the wild type, but not in lpxE::cat, may represent forms of LPS in which the lipid A moiety has been dephosphorylated at the 1-position. It is also possible that, in these bands, the core may have undergone further modification subsequent to lipid A dephosphorylation (see Discussion).

The LPS gel results described above (Figure 9C) contrasted with the outcome of whole cell ELISA analysis of the lpxE::cat strain. This mutant strain retained its capacity to respond to cholesterol availability with enhanced surface Lewis $\mathrm{X}$ and Lewis $\mathrm{Y}$ expression (Figure 10, Table 2), as did the eptA::cat strain (data not shown) and the cgt::cat strain 


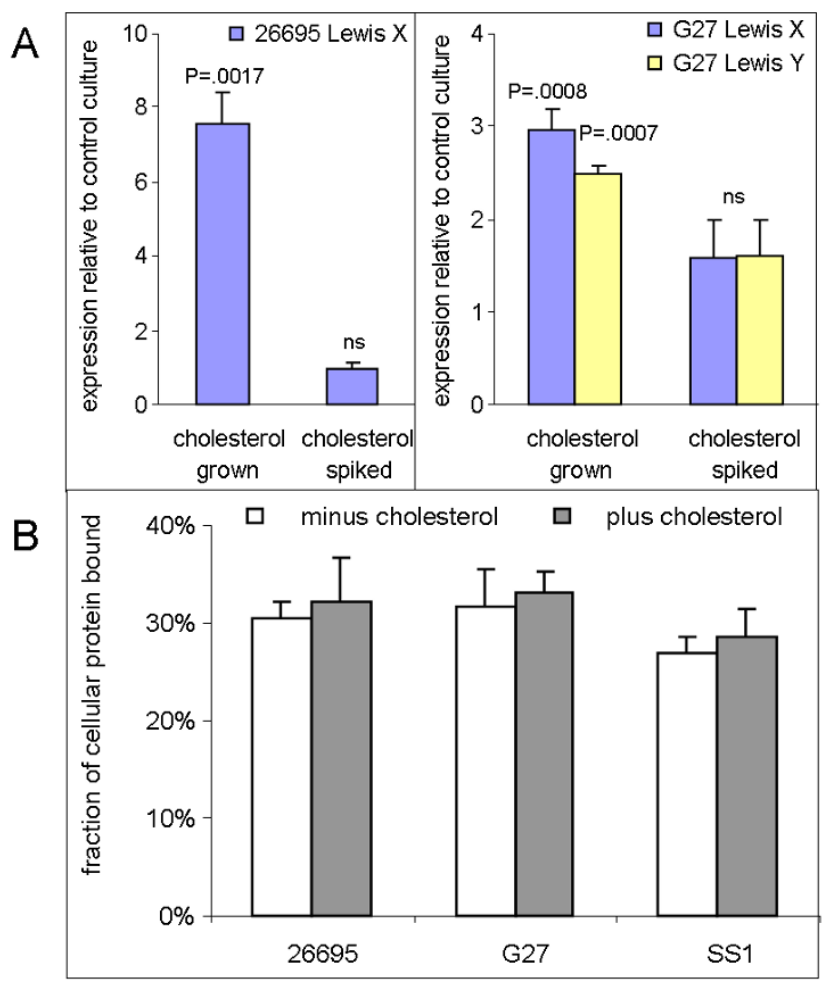

Figure 5

ELISA control experiments. A. Spiking with cholesterol at the end of the growth period does not alter Lewis antigen expression. Cultures of $H$. pylori were grown overnight in defined medium without (control) or with $50 \mu \mathrm{g} / \mathrm{ml}$ cholesterol (cholesterol grown). A third flask (cholesterol spiked) was grown in the absence of cholesterol, chilled on ice, and an equivalent amount of cholesterol was added before the cells were harvested. Lewis antigens were quantitated in duplicate by whole-cell ELISA, loading $300 \mathrm{ng}$ cellular protein per well. Ratios for plus:minus cholesterol were calculated from average net absorbance readings in each assay, and the plot displays mean ratios \pm sem for three to five independent ELISA runs. $P$ values were calculated in two-tailed Student t-tests for the null hypothesis that the ratio equals I. For comparisons labeled ns, P > .05. B.

Equivalent binding of cells to ELISA plates. Samples of $H$. pylori that were grown in parallel cultures in the absence (white bars) or presence of $50 \mu \mathrm{g} / \mathrm{ml}$ cholesterol (grey bars) were applied to multiwell plates in the same manner as for Lewis antigen ELISA assays, adding $500 \mathrm{ng}$ of cellular protein per well. Following overnight attachment, wells were washed twice with Dulbecco's phosphate-buffered saline, then protein in adherent cells was quantitated using the BCA reagent. Mean values \pm sd of quadruplicate wells are shown.

(Fig. 10). These contrasting results show that the enhanced surface display of Lewis antigen in response to growth in cholesterol occurred independently of the structural modifications to the core/lipid A moiety seen on silver-stained gels.

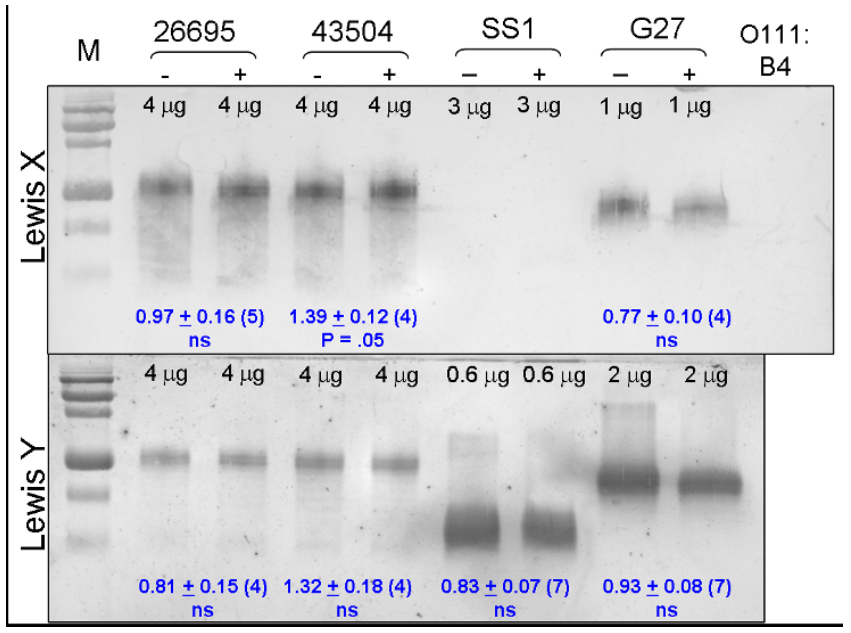

Figure 6

Lewis $X$ and $Y$ antigen profiling by immunoblotting. Samples of LPS isolated from parallel cultures grown in the absence (-) or presence (+) of $50 \mu \mathrm{g} / \mathrm{ml}$ cholesterol were resolved on I $5 \%$ urea gels. Quantities loaded per lane, as $\mu \mathrm{g}$ of initial lysate protein, are given at the top of each lane. Following transfer, antigens were immunodetected with monoclonal antibodies specific for Lewis $X$ (upper panel) or Lewis $Y$ (lower panel). A representative example of each is shown. Side lanes contain prestained protein markers (M) or $400 \mathrm{ng}$ of E. coli OIII:B4 LPS. Antigenic signal appeared only in the $O$-chain regions of these $H$. pylori strains; blank areas have been cropped out accordingly. The immunoblots were independently replicated with several sample sets, and densitometry was used to quantitate antigen signal in each lane. Ratios for pairwise plus:minus cholesterol samples were calculated, and the mean ratios \pm sem for $(n)$ blots are given in blue. The null hypothesis that the ratio equals I was evaluated in a twotailed Student t-test.

\section{Discussion}

In eukaryotic membranes, cholesterol modulates curvature and fluidity, and cholesterol-rich lipid subdomains influence numerous membrane functions, including signal transduction and transport activity [59], yet very little is known about the physiological roles of cholesterol among the prokaryotes that utilize it. In this study, we used chemically defined medium to begin to characterize these roles of cholesterol in H. pylori. Growth of H. pylori in the presence of cholesterol proved to be essential for gastric colonization in the gerbil, even though it is not necessary for growth in vitro. This colonization experiment was conducted under standard dietary conditions, where cholesterol should be abundant in gastric mucus $[2,3,60]$. Taking into account that $H$. pylori can also acquire cholesterol from the membrane of host gastric epithelial cells [35], our data would suggest that incorporation of cholesterol into the bacterial membrane prior to inoculation may facilitate early steps in gastric colonization that precede adherence to host epithelium, such as motility and/ 


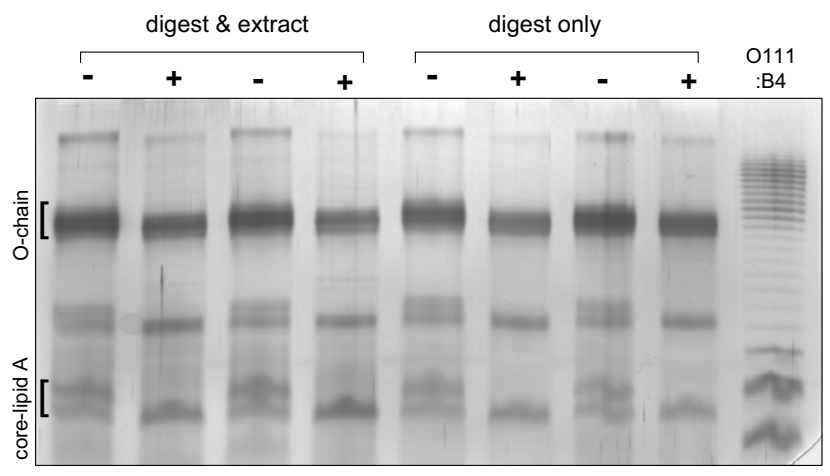

\section{Figure 7}

G27 LPS species are quantitatively recovered in purified preparations, and respond to cholesterol in the growth medium. In two independent experiments, parallel cultures of $H$. pylori strain G27 were grown overnight in defined medium without (-) or with (+) $50 \mu \mathrm{g} / \mathrm{ml}$ cholesterol. Cell lysates were digested with proteinase $\mathrm{K}$, and portions of each lysate were further purified by hot phenol extraction and alcohol precipitation. Aliquots taken after digest only or after the extraction/precipitation procedure were resolved on a $15 \%$ urea gel. Each lane represents an amount of sample material derived from an equivalent amount of the initial cell lysate ( $2 \mu \mathrm{g}$ protein). The reference lane contains $400 \mathrm{ng}$ of LPS from $E$. coli OI I I:B4 as a silver staining control. No bands were selectively gained or lost in the workup following proteolytic digestion.

or acid resistance. Preliminary experiments have indicated that $H$. pylori grown in the presence of cholesterol are more resistant to acid and oxidative stresses than when cholesterol-depleted (DJM, unpublished observations). We propose that incorporation of cholesterol and/or cholesterol metabolites may strengthen the bacterial membrane against such stresses, protecting the bacterium from gastric acid prior to entry into the more $\mathrm{pH}$-neutral gastric mucus layer. Once the epithelial layer has been colonized, host-derived cholesterol may then be utilized.

We have also presented evidence of a role for cholesterol in establishment of the normal lipopolysaccharide component of the cell envelope. Both Lewis antigen[12,14] and core oligosaccharide $[13,61,62]$ contribute to $H$. pylori adherence and colonization. We have demonstrated here that cholesterol supports both increased display of Lewis $\mathrm{X}$ and $\mathrm{Y}$ antigens as well as the modification of LPS core/ lipid A structure. These responses do not require cholesterol $\alpha$-glycosides, but are nevertheless highly specific for cholesterol. No changes in Lewis antigen levels or in LPS profiles occurred when cholesterol was substituted by the structurally very similar $\beta$-sitosterol or other steroidal substances. There is experimental evidence for specific, protein-mediated cholesterol uptake by $H$. pylori [27], but no receptor has so far been identified.

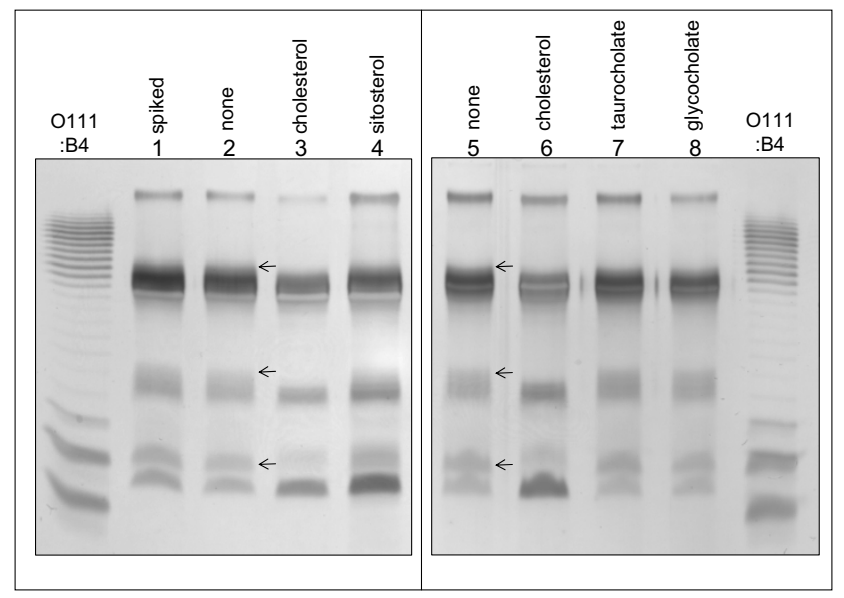

\section{Figure 8}

LPS structure in $H$. pylori strain $\mathbf{G} 27$ responds specifically to growth in cholesterol. In two independent experiments, parallel cultures of $H$. pylori strain G27 were grown overnight in defined medium. The growth media contained the following, each at I $30 \mu \mathrm{M}$ : lanes I, 2, 5, no addition; lanes 3, 6, cholesterol; lane 4, synthetic $\beta$-sitosterol; lane 7, taurocholate; lane 8, glycocholate. At the end of the growth period the cultures were chilled on ice, and an equivalent amount of cholesterol was then added to sample I. Cell lysates were adjusted to equal protein content, digested with proteinase $\mathrm{K}$, and resolved on a $15 \%$ urea gel as described in Methods. Sample amounts loaded per lane correspond to 3 $\mu \mathrm{g}$ of cellular protein (lanes 1-4), or $2 \mu \mathrm{g}$ (lanes 5-8). The indicated reference lane contains $400 \mathrm{ng}$ of purified LPS from E. coli strain OIII:B4. Arrows mark the specific bands that diminish in cholesterol-grown cultures.

In the clinical strain G27, specific LPS bands are observed under conditions of cholesterol depletion that do not occur upon growth in complex or defined media containing cholesterol. This suggests a requirement for cholesterol in the normal maturation of structure during LPS biosynthesis. Determination of the structure of LPS in G27, and identification of cholesterol-dependent changes to this structure, are currently in progress. We anticipate that cholesterol-dependent changes will likely be found within the core/lipid A portion of the LPS, because we also observed LPS band changes in isogenic strains that lack the O-chain. The loss of LPS O-chains by disruption of $p m i$ was unexpected, as an NCTC11637 strain with a disruption in the same gene retained the O-chain [14]. We do not presently know why the LPS phenotype of the latter mutant differs from the pmi::cat strains that we generated using an allelic replacement strategy. Investigation of this matter is ongoing and will be the subject of another report. Directing our attention to the core/lipid A moieties, we attempted to identify LPS biosynthesis genes that, when disabled, would eliminate the observed LPS responses to cholesterol. We selected two genes, $l p x E$ and 


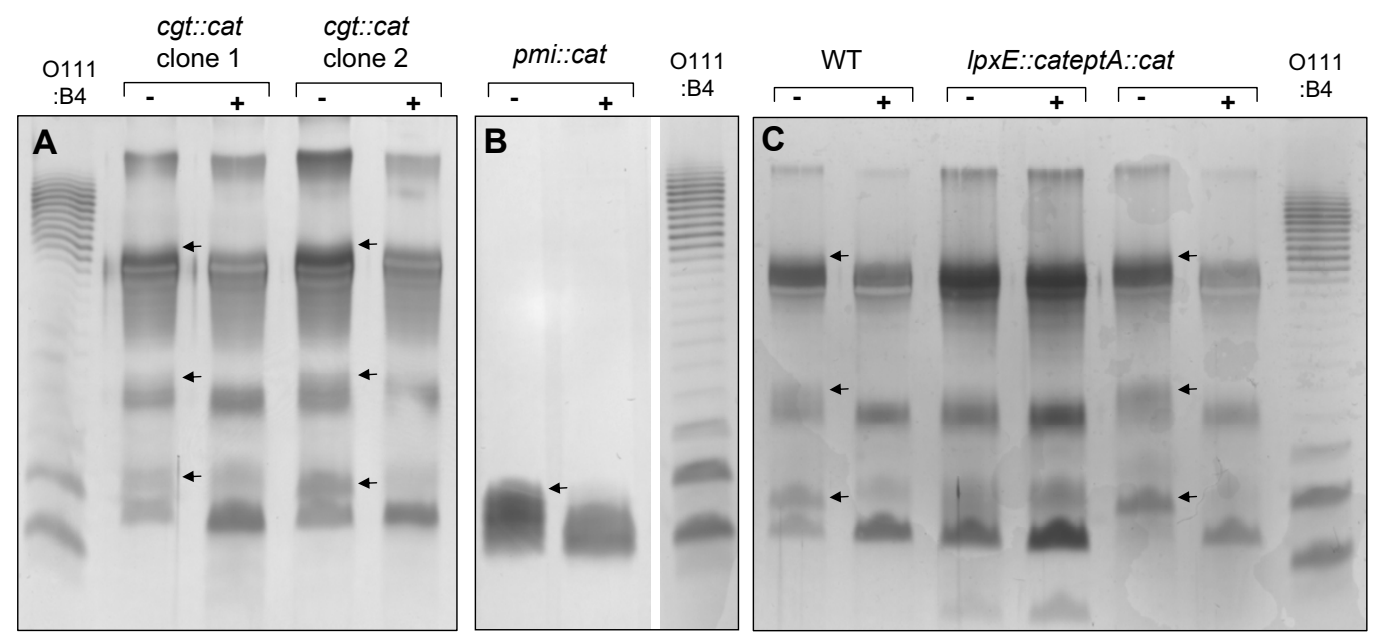

\section{Figure 9}

Influence of selective gene disruptions on G27 LPS response to cholesterol availability. In each experiment, parallel cultures of genetically altered G27 strains were grown overnight in defined medium without (-) or with (+) $50 \mu \mathrm{g} / \mathrm{ml}$ cholesterol. Cell lysates were adjusted to equal protein content, digested with proteinase $\mathrm{K}$, and resolved on a $15 \%$ urea gel as described in Methods. Sample amounts loaded per lane correspond to $2 \mu \mathrm{g}$ of cellular protein. Reference lanes contain $400 \mathrm{ng}$ of purified LPS from E. coli strain OI I I:B4. A. LPS preparations from pairwise minus- and plus-cholesterol cultures of two individual cgt::cat G27 transformants. B. LPS from pairwise cultures of the O-chain-lacking pmi::cat G27 strain. C. LPS from pairwise cultures of wild type G27, or of isogenic lpxE::cat or eptA::cat strains.

eptA, that sequentially remove the lipid A 1-phosphate group and add 1-phosphoethanolamine [58]. Disruption of eptA did not affect cholesterol-dependent changes in the LPS profile, but disruption of $l p x E$ eliminated this response to cholesterol. We propose that the LPS bands seen only under conditions of cholesterol depletion represent LPS with modified lipid A structure. This modified form could be 1-dephospholipid A, or a downstream form thereof (not including the 1-phosphoethanolamine form, which is ruled out by our eptA::cat results). While the entire sequence of LPS biogenesis has not been worked out in H. pylori, a ketodeoxyoctulosonic acid (Kdo) hydrolase activity has been detected in membrane fractions of $H$. pylori that removes the outermost of two Kdo residues subsequent to lipid A dephosphorylation [63]. Though to date no Kdo hydrolase gene has been identified, such a Kdo-modified derivative may be considered a candidate for the modified LPS. There may be other as yet unidentified downstream modifications as well. Positive assignment of the bands we observed is further complicated by the existence of a minor LPS form, in which lipid A bears an extra 4-phosphate group, and is hexa- rather than tetra-acylated [23]. Lipid A modifications are important because they strongly influence Tolllike receptor recognition, modulating innate immune responses $[23,64]$.

In order to discuss potential mechanisms for these LPS effects, we must consider the architecture of LPS biosyn- thesis. In well-studied organisms such as E. coli, the numerous steps in LPS biogenesis take place in specific subcellular compartments, and require specific transporters to shuttle intermediates across the inner membrane, periplasmic space, and outer membrane [64,65]. $\mathrm{Kdo}_{2}-$ lipid A is synthesized on the cytoplasmic face of the inner membrane, where the core oligosaccharide is separately assembled and then attached. This core-lipid A species must be flipped across the bilayer by the essential transporter MsbA. Modifications to lipid A are then carried out on the periplasmic face of the inner membrane. The $\mathrm{O}$ chain is independently assembled in the cytoplasm on an undecaprenyl diphosphate carrier, transported across the inner membrane, and attached to the core-lipid A periplasmically. The multicomponent Lpt assembly transports full-length LPS across the outer membrane, where further trimming may occur. LPS biogenesis is species-specific, and for the case of $H$. pylori the picture is much less complete. Some but not all of the expected LPS transporter subunits have been identified in the genome $[66,67]$. Lipid A dephosphorylation and phosphoethanolamine addition have been assigned to the periplasmic compartment based on work in which these $H$. pylori genes were expressed in a temperature-sensitive MsbA mutant strain of E. coli [58]. Our data are consistent with periplasmic lipid A modification occurring independently of both $\mathrm{O}$-chain addition and Lewis antigen addition, in keeping with the general model just described. This distinctly ordered process gives rise to a defined range of LPS 


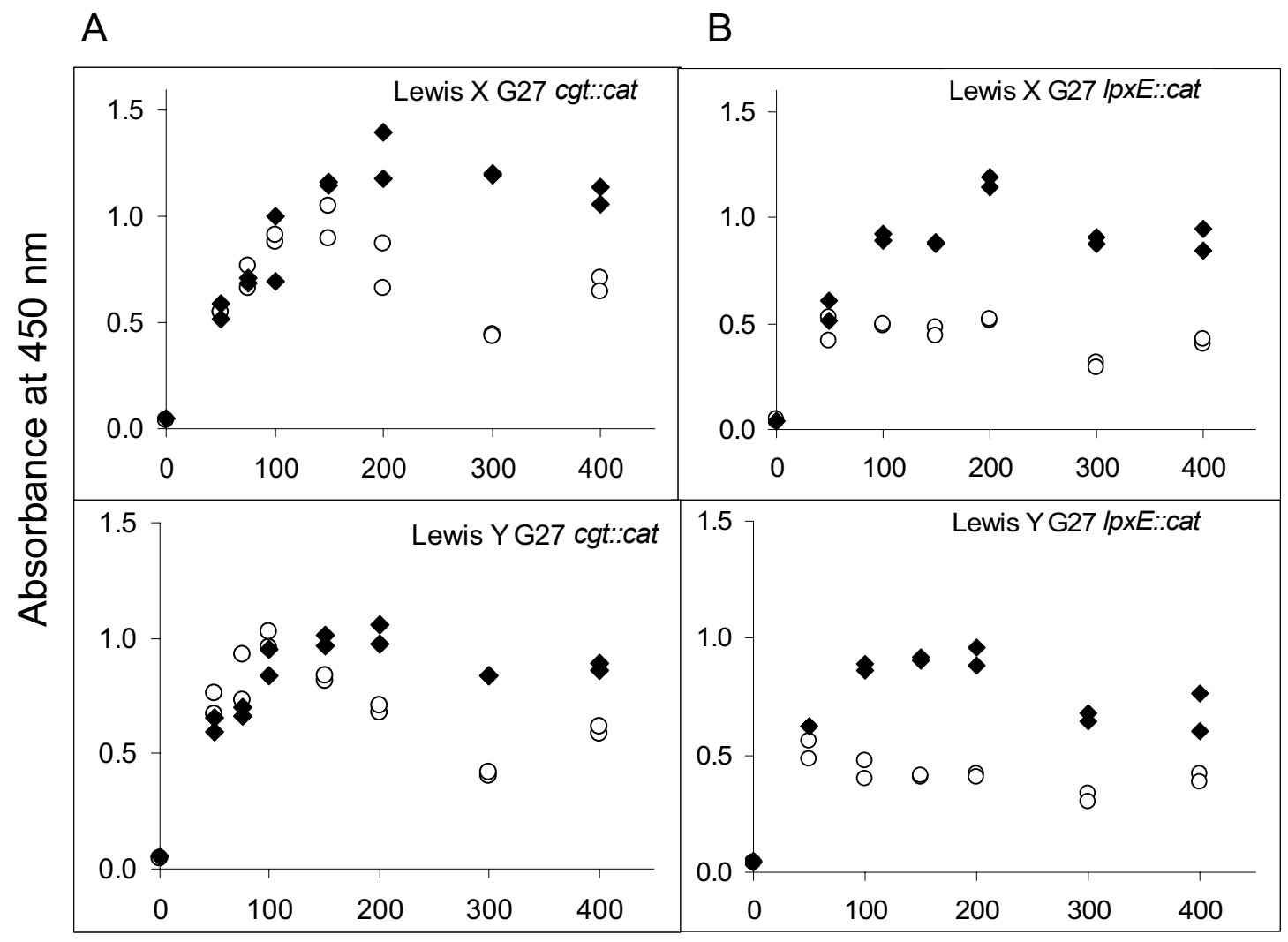

ng protein per well

\section{Figure 10}

H. pylori G27 retain Lewis antigen response to cholesterol after disruption of cgt or lpxE. Whole cell ELISA assays were performed in duplicate on samples of $H$. pylori G27 cgt::cat (panel A) or lpxE::cat (panel B), which were cultured in parallel in the absence (open symbols) or presence of cholesterol (filled symbols). Absorbance readings for individual wells are plotted.

molecules at the cell surface. Importantly, the LPS array can be remodeled in response to environmental conditions such as external $\mathrm{pH}[68,69]$.

How then might cholesterol modulate LPS biogenesis and modification? The lipid compositions of the inner and outer membranes of gram negative bacteria are specific and distinct [70], but little is known about the subcellular compartmentation of cholesterol in $\mathrm{H}$. pylori or other prokaryotes. We propose that the presence of cholesterol is needed to establish the proper membrane composition and structure that permit the orderly building of nascent LPS as it transits across the inner membrane/periplasmic/ outer membrane compartments. In this model, altered membrane composition may influence the activity of LPS biosynthetic enzymes embedded in the membrane, leading to improper LPS modification. Alternatively, cholesterol depletion may result in dysregulation of LPS transporter function due to alterations in membrane structure and composition. The dysregulated movement of LPS among inner membrane, periplasmic, and outer membrane compartments would then result in aberrant modifications to its structure. This scenario would be consistent with the observed discrepancy between whole cell Lewis antigen levels measured by immunoblot and cell surface levels measured by ELISA. That is, it is possible that under cholesterol-depletion the Lewis antigen-bearing LPS may be less effectively transported to the cell surface. Preliminary evidence indicates that membrane cholesterol may also influence certain $\mathrm{ABC}$ transporters and the ComB DNA transporter in H. pylori (Hildebrandt, Trainor and McGee, unpublished results). Thus, cholesterol may support a wider range of physiological processes in the bacterial membrane than is currently appreciated.

\section{Conclusions}

We have demonstrated for the first time that cholesterol, though nonessential to growth of $H$. pylori, is nevertheless essential for gastric colonization in an animal model. We have further shown that cholesterol plays important roles 
in determining LPS structure as well as Lewis antigen expression, and that these biological effects are highly specific for cholesterol. LPS profiles of mutant strains lacking the O-chain retain responses to cholesterol availability, providing evidence for structural changes to the oligosaccharide core/lipid A moieties. Disruption of the lipid A 1phosphatase gene, $l p x E$, eliminated the effect of cholesterol on LPS profiles, suggesting that aberrant forms of LPS that appear upon cholesterol depletion are dependent upon 1-dephosphorylation of lipid A. The roles of cholesterol in LPS structural modification and in Lewis antigen expression do not require $\alpha$-glucosylation of cholesterol. Thus, cholesterol imparts these benefits independently of its previously reported role in resistance to host phagocytosis and T-cell responses, which require the alpha-glycoside metabolite of cholesterol [35]. Together these studies serve to emphasize the critical roles that cholesterol and its metabolites in the $H$. pylori membrane can play in hostpathogen interactions.

\section{Authors' contributions}

DJM participated in animal experiments, oversaw development of the study, and edited the manuscript. EH contributed to study development, carried out molecular genetic and analytical work, participated in animal experiments, and drafted the manuscript. Both authors have read and approved the final manuscript.

\section{Acknowledgements}

This work was supported by Public Health Service grant ROICA I0193I from the National Institutes of Health and by a Bridge Award from LSUHSC-S. Our colleagues Ken Peterson and Daniel Shelver took part in discussions of the work in progress. Traci Testerman shared bacterial stocks and participated in discussions. John Staczek donated laboratory supplies, and critiqued a preliminary version of this manuscript.

\section{References}

I. Amieva MR, El-Omar EM: Host-bacterial interactions in Helicobacter pylori infection. Gastroenterology 2008, I 34(I):306-323.

2. Slomiany A, Yano S, Slomiany BL, Glass GB: Lipid composition of the gastric mucous barrier in the rat. J Biol Chem 1978, 253(I I):3785-379I.

3. Gong DH, Turner B, Bhaskar KR, Lamont JT: Lipid binding to gastric mucin: protective effect against oxygen radicals. $A m \mathrm{~J}$ Physiol 1990, 259(4 Pt I):G68I-686.

4. Sherburne R, Taylor DE: Helicobacter pylori expresses a complex surface carbohydrate, Lewis $X$. Infect Immun 1995, 63( I 2):4564-4568.

5. Aspinall GO, Monteiro MA: Lipopolysaccharides of Helicobacter pylori strains P466 and MOI9: structures of the $O$ antigen and core oligosaccharide regions. Biochemistry 1996, 35(7):2498-2504.

6. Simoons-Smit IM, Appelmelk BJ, Verboom T, Negrini R, Penner JL, Aspinall GO, Moran AP, Fei SF, Shi BS, Rudnica W, et al.: Typing of Helicobacter pylori with monoclonal antibodies against Lewis antigens in lipopolysaccharide. J Clin Microbiol 1996, 34(9):2196-2200.

7. Wirth HP, Yang M, Karita M, Blaser MJ: Expression of the human cell surface glycoconjugates Lewis $x$ and Lewis $y$ by Helicobacter pylori isolates is related to cagA status. Infect Immun I 996, 64(I I):4598-4605.

8. Monteiro MA, Chan KH, Rasko DA, Taylor DE, Zheng PY, Appelmelk BJ, Wirth HP, Yang M, Blaser MJ, Hynes SO, et al.: Simultaneous expression of type I and type 2 Lewis blood group antigens by Helicobacter pylori lipopolysaccharides. Molecular mimicry between $H$. pylori lipopolysaccharides and human gastric epithelial cell surface glycoforms. J Biol Chem 1998, 273( I9): I I 533-I I543.

9. Monteiro MA, Zheng P, Ho B, Yokota S, Amano K, Pan Z, Berg DE, Chan $\mathrm{KH}$, MacLean LL, Perry MB: Expression of histo-blood group antigens by lipopolysaccharides of Helicobacter pylori strains from asian hosts: the propensity to express type I blood-group antigens. Glycobiology 2000, I0(7):701-7I3.

10. Appelmelk BJ, Monteiro MA, Martin SL, Moran AP, VandenbrouckeGrauls CM: Why Helicobacter pylori has Lewis antigens. Trends Microbiol 2000, 8( I 2):565-570.

II. Logan SM, Conlan JW, Monteiro MA, Wakarchuk WW, Altman E: Functional genomics of Helicobacter pylori: identification of a beta- I,4 galactosyltransferase and generation of mutants with altered lipopolysaccharide. Mol Microbiol 2000, 35(5): I I56-II67.

12. Moran AP, Sturegard E, Sjunnesson H, Wadstrom T, Hynes SO: The relationship between $O$-chain expression and colonisation ability of Helicobacter pylori in a mouse model. FEMS Immunol Med Microbiol 2000, 29(4):263-270.

13. Altman E, Chandan V, Larocque S, Aubry A, Logan SM, Vinogradov E, $\mathrm{Li}$ J: Effect of the HPOI59 ORF mutation on the lipopolysaccharide structure and colonizing ability of Helicobacter pylori. FEMS Immunol Med Microbiol 2008, 53(2):204-2I 3.

14. Edwards NJ, Monteiro MA, Faller G, Walsh EJ, Moran AP, Roberts IS, High NJ: Lewis $\mathbf{X}$ structures in the $\mathbf{O}$ antigen side-chain promote adhesion of Helicobacter pylori to the gastric epithelium. Mol Microbiol 2000, 35(6): I530-I539.

I5. Falk P, Roth KA, Boren T, Westblom TU, Gordon JI, Normark S: An in vitro adherence assay reveals that Helicobacter pylori exhibits cell lineage-specific tropism in the human gastric epithelium. Proc Natl Acad Sci USA 1993, 90(5):2035-2039.

16. Thoreson AC, Hamlet A, Celik J, Bystrom M, Nystrom S, Olbe L, Svennerholm AM: Differences in surface-exposed antigen expression between Helicobacter pylori strains isolated from duodenal ulcer patients and from asymptomatic subjects. J Clin Microbiol 2000, 38(9):3436-344I.

17. Gonzalez-Valencia G, Munoz-Perez L, Morales-Espinosa R, Camorlinga-Ponce $M$, Munoz $O$, Torres $\mathrm{J}$ : Lewis antigen expression by Helicobacter pylori strains colonizing different regions of the stomach of individual patients. J Clin Microbiol 2008, 46(8):2783-2785.

18. Taylor DE, Rasko DA, Sherburne R, Ho C, Jewell LD: Lack of correlation between Lewis antigen expression by Helicobacter pylori and gastric epithelial cells in infected patients. Gastroenterology 1998, I I 5(5): I I I3- I I 22.

19. Mollicone R, Bara J, Le Pendu J, Oriol R: Immunohistologic pattern of type I (Lea, Leb) and type 2 (X, Y, H) blood grouprelated antigens in the human pyloric and duodenal mucosae. Lab Invest 1985, 53(2):219-227.

20. Wirth HP, Yang M, Peek RM Jr, Hook-Nikanne J, Fried M, Blaser MJ: Phenotypic diversity in Lewis expression of Helicobacter pylori isolates from the same host. J Lab Clin Med 1999, I33(5):488-500.

21. Wirth HP, Yang M, Sanabria-Valentin E, Berg DE, Dubois A, Blaser MJ: Host Lewis phenotype-dependent Helicobacter pylori Lewis antigen expression in rhesus monkeys. Faseb J 2006, 20(9): I534-I536.

22. Zheng PY, Tang FA, Qi YM, Li J: Association of peptic ulcer with increased expression of Lewis antigens, but not vacuolating cytotoxin activity or babA2 gene status, in Helicobacter pylori strains from China. Chin J Dig Dis 2006, 7(I):6I-65.

23. Moran AP, Lindner B, Walsh Ej: Structural characterization of the lipid A component of Helicobacter pylori rough- and smooth-form lipopolysaccharides. I Bacteriol 1997, I 79(20):6453-6463.

24. Moran AP: Molecular structure, biosynthesis, and pathogenic roles of lipopolysaccharides. In Helicobacter pylori: Physiology and Genetics Edited by: Mobley HLT, Mendz GL, Hazell SL. Herndon, VA: ASM Press; 2001:81-95.

25. Albertson N, Wenngren I, Sjostrom JE: Growth and survival of Helicobacter pylori in defined medium and susceptibility to Brij 78. J Clin Microbiol I 998, 36(5): I 232-I 235. 
26. Testerman TL, McGee DJ, Mobley HL: Helicobacter pylori growth and urease detection in the chemically defined medium Ham's F-12 nutrient mixture. J Clin Microbiol 200I, 39(II):3842-3850.

27. Trampenau C, Muller KD: Affinity of Helicobacter pylori to cholesterol and other steroids. Microbes Infect 2003, 5(I): I3-I7.

28. Razin S: Cholesterol incorporation into bacterial membranes. J Bacteriol 1975, I 24(1):570-572.

29. Ben-Menachem G, Kubler-Kielb J, Coxon B, Yergey A, Schneerson R: A newly discovered cholesteryl galactoside from Borrelia burgdorferi. Proc Natl Acad Sci USA 2003, 100 (13):79|3-79|8.

30. Noh DO, Kim SH, Gilliland SE: Incorporation of cholesterol into the cellular membrane of Lactobacillus acidophilus ATCC 43 I 2 I. J Dairy Sci 1997, 80( I 2):3 I07-3। I3.

31. Razin S: The cell membrane of mycoplasma. Ann N Y Acad Sci 1967, I43(I): II5-129.

32. Rodwell AW, Abbot A: The function of glycerol, cholesterol and long-chain fatty acids in the nutrition of Mycoplasma mycoides. J Gen Microbiol I96I, 25:20I-2I4.

33. Haque M, Hirai Y, Yokota K, Mori N, Jahan I, Ito H, Hotta H, Yano I, Kanemasa Y, Oguma K: Lipid profile of Helicobacter spp.: presence of cholesteryl glucoside as a characteristic feature. J Bacteriol 1996, I 78(7):2065-2070.

34. Hirai Y, Haque M, Yoshida T, Yokota K, Yasuda T, Oguma K: Unique cholesteryl glucosides in Helicobacter pylori: composition and structural analysis. J Bacteriol 1995, I77( I 8):5327-5333.

35. Wunder C, Churin Y, Winau F, Warnecke D, Vieth M, Lindner B, Zahringer U, Mollenkopf HJ, Heinz E, Meyer TF: Cholesterol glucosylation promotes immune evasion by Helicobacter pylori. Nat Med 2006, I2(9): 1030-1038.

36. Xiang Z, Censini S, Bayeli PF, Telford IL, Figura N, Rappuoli R, Covacci $A$ : Analysis of expression of CagA and VacA virulence factors in 43 strains of Helicobacter pylori reveals that clinical isolates can be divided into two major types and that CagA is not necessary for expression of the vacuolating cytotoxin. Infect Immun 1995, 63(I):94-98.

37. Lee A, O'Rourke J, De Ungria MC, Robertson B, Daskalopoulos G, Dixon MF: A standardized mouse model of Helicobacter pylori infection: introducing the Sydney strain. Gastroenterology 1997, I I 2(4): I386-1397.

38. Linstead D: New defined and semi-defined media for cultivation of the flagellate Trichomonas vaginalis. Parasitology I98I, 83(Pt I): 125-137.

39. Testerman TL, Conn PB, Mobley HL, McGee DJ: Nutritional requirements and antibiotic resistance patterns of Helicobacter species in chemically defined media. J Clin Microbiol 2006, 44(5): 1650-1658.

40. Hattori N, Sakakibara T, Kajiyama N, Igarashi T, Maeda M, Murakami $\mathrm{S}$ : Enhanced microbial biomass assay using mutant luciferase resistant to benzalkonium chloride. Anal Biochem 2003, 3 I 9(2):287-295.

4I. Chalker AF, Minehart HW, Hughes NJ, Koretke KK, Lonetto MA, Brinkman KK, Warren PV, Lupas A, Stanhope MJ, Brown JR, et al:: Systematic identification of selective essential genes in Helicobacter pylori by genome prioritization and allelic replacement mutagenesis. J Bacteriol 200I, I 83(4): I259-I 268.

42. Wang Y, Roos KP, Taylor DE: Transformation of Helicobacter pylori by chromosomal metronidazole resistance and by a plasmid with a selectable chloramphenicol resistance marker. J Gen Microbiol 1993, I39( I 0):2485-2493.

43. Joseph B, Beier D: Global analysis of two-component gene regulation in $\mathrm{H}$. pylori by mutation analysis and transcriptional profiling. Methods Enzymol 2007, 423:5I4-530.

44. Langford ML, Zabaleta J, Ochoa AC, Testerman TL, McGee DJ: In vitro and in vivo complementation of the Helicobacter pylori arginase mutant using an intergenic chromosomal site. Helicobacter 2006, I I(5):477-493.

45. Nelson D, Neill W, Poxton IR: A comparison of immunoblotting, flow cytometry and ELISA to monitor the binding of anti-lipopolysaccharide monoclonal antibodies. I Immunol Methods 1990, I33(2):227-233.

46. Hosoda H, Takasaki W, Oe T, Tsukamoto R, Nambara T: A comparison of chromogenic substrates for horseradish peroxidase as a label in steroid enzyme immunoassay. Chem Pharm Bull (Tokyo) I986, 34(I0):4177-4I82.
47. Hitchcock PJ, Brown TM: Morphological heterogeneity among Salmonella lipopolysaccharide chemotypes in silver-stained polyacrylamide gels. J Bacteriol I983, I54(I):269-277.

48. Westphal O, Jann K: Bacterial lipopolysaccharides. Extraction with phenol-water and further applications of the procedure. Methods in Carbohydrate Chemistry 1965, 5:83-91.

49. Laemmli UK: Cleavage of structural proteins during the assembly of the head of bacteriophage T4. Nature 1970, 227(5259):680-685.

50. Tsai CM, Frasch CE: A sensitive silver stain for detecting lipopolysaccharides in polyacrylamide gels. Anal Biochem 1982, II9(I):II5-II9.

5I. Towbin H, Staehelin T, Gordon J: Electrophoretic transfer of proteins from polyacrylamide gels to nitrocellulose sheets: procedure and some applications. Proc Natl Acad Sci USA 1979, 76(9):4350-4354

52. Pukac LA, Carter JE, Morrison KS, Karnovsky MJ: Enhancement of diaminobenzidine colorimetric signal in immunoblotting. Biotechniques 1997, 23(3):385-388.

53. Williams JC, Mclnnis KA, Testerman TL: Adherence of Helicobacter pylori to abiotic surfaces is influenced by serum. Appl Environ Microbiol 2008, 74(4): I255-I 258.

54. Appelmelk BJ, Martino MC, Veenhof E, Monteiro MA, Maaskant II, Negrini R, Lindh F, Perry M, Del Giudice G, Vandenbroucke-Grauls CM: Phase variation in $\mathbf{H}$ type $\mathbf{I}$ and Lewis a epitopes of Helicobacter pylori lipopolysaccharide. Infect Immun 2000, 68(10):5928-5932.

55. Monteiro MA, Appelmelk B], Rasko DA, Moran AP, Hynes SO, MacLean LL, Chan KH, Michael FS, Logan SM, O'Rourke J, et al: Lipopolysaccharide structures of Helicobacter pylori genomic strains 26695 and J99, mouse model $H$. pylori Sydney strain, $H$. pylori P466 carrying sialyl Lewis $X$, and $H$. pylori UA9 I5 expressing Lewis B. Classification of $\boldsymbol{H}$. pylori lipopolysaccharides into glycotype families. Eur I Biochem 2000, 267(2):305-320.

56. Pathak SS, van Oudenaren A, Savelkout HFJ: Quantification of immunoglobulin concentration by ELISA. In Immunology Methods Manual Volume 2. Edited by: Lefkovits I. San Diego, CA: Academic Press; 1997:1055-1075.

57. Aspinall GO, Monteiro MA, Pang H, Walsh EJ, Moran AP: Lipopolysaccharide of the Helicobacter pylori type strain NCTC I 1637 (ATCC 43504): structure of the $O$ antigen chain and core oligosaccharide regions. Biochemistry 1996, 35(7):2489-2497.

58. Tran AX, Karbarz MJ, Wang X, Raetz CR, McGrath SC, Cotter RJ, Trent MS: Periplasmic cleavage and modification of the Iphosphate group of Helicobacter pylori lipid A. J Biol Chem 2004, 279(53):55780-5579l.

59. Ikonen E: Cellular cholesterol trafficking and compartmentalization. Nat Rev Mol Cell Biol 2008, 9(2): I 25-138.

60. Iwamori M, Suzuki H, Ito N, Iwamori Y, Hanaoka K: Lipid compositions of human gastric fluid and epithelium: the role of sulfated lipids in gastric cytoprotection. J Clin Gastroenterol 2005, 39(2): 129-133.

6I. Altman E, Smirnova N, Li J, Aubry A, Logan SM: Occurrence of a nontypable Helicobacter pylori strain lacking Lewis blood group $O$ antigens and DD-heptoglycan: evidence for the role of the core alpha I,6-glucan chain in colonization. Glycobiology 2003, I3 (I I):777-783.

62. Reeves EP, Ali T, Leonard P, Hearty S, O'Kennedy R, May FE, Westley BR, Josenhans C, Rust M, Suerbaum S, et al.: Helicobacter pylori lipopolysaccharide interacts with TFFI in a pH-dependent manner. Gastroenterology 2008, 135(6):2043-2054.

63. Stead C, Tran A, Ferguson D Jr, McGrath S, Cotter R, Trent S: A novel 3-deoxy-D-manno-octulosonic acid (Kdo) hydrolase that removes the outer Kdo sugar of Helicobacter pylori lipopolysaccharide. J Bacteriol 2005, I 87( I 0):3374-3383.

64. Raetz CR, Reynolds CM, Trent MS, Bishop RE: Lipid A modification systems in gram-negative bacteria. Annu Rev Biochem 2007, 76:295-329.

65. Sperandeo P, Deho G, Polissi A: The lipopolysaccharide transport system of Gram-negative bacteria. Biochim Biophys Acta 2009, I791:594-602.

66. Tomb JF, White O, Kerlavage AR, Clayton RA, Sutton GG, Fleischmann RD, Ketchum KA, Klenk HP, Gill S, Dougherty BA, et al.: The complete genome sequence of the gastric pathogen Helicobacter pylori. Nature 1997, 388(6642):539-547. 
67. Baltrus DA, Amieva MR, Covacci A, Lowe TM, Merrell DS, Ottemann KM, Stein M, Salama NR, Guillemin K: The complete genome sequence of Helicobacter pylori strain G27. J Bacteriol 2009, I 91 ( I):447-448.

68. Moran AP, Knirel YA, Senchenkova SN, Widmalm G, Hynes SO, Jansson PE: Phenotypic variation in molecular mimicry between Helicobacter pylori lipopolysaccharides and human gastric epithelial cell surface glycoforms. Acid-induced phase variation in Lewis(x) and Lewis(y) expression by $\mathrm{H}$. pylori lipopolysaccharides. J Biol Chem 2002, 277(8):5785-5795.

69. McGowan CC, Necheva A, Thompson SA, Cover TL, Blaser MJ: Acid-induced expression of an LPS-associated gene in Helicobacter pylori. Mol Microbiol 1998, 30(1): |9-31.

70. Osborn MJ, Munson R: Separation of the inner (cytoplasmic) and outer membranes of Gram-negative bacteria. Methods Enzymol 1974, 3 I (Pt A):642-653.

Publish with Bio Med Central and every scientist can read your work free of charge

"BioMed Central will be the most significant development for disseminating the results of biomedical research in our lifetime. "

Sir Paul Nurse, Cancer Research UK

Your research papers will be:

- available free of charge to the entire biomedical community

- peer reviewed and published immediately upon acceptance

- cited in PubMed and archived on PubMed Central

- yours - you keep the copyright

Submit your manuscript here:

http://www.biomedcentral.com/info/publishing_adv.asp
BioMedcentral 